\title{
Crianças e televisão: o que elas pensam sobre o que aprendem com a tevê $\hat{~}^{*}$
}

\author{
Rosália Duarte, Camila Leite, Rita Migliora \\ Pontifícia Universidade Católica do Rio de Janeiro, Grupo de Pesquisa de Educação e Mídia
}

\section{Introdução}

Este artigo apresenta resultados da pesquisa “Crianças e televisão", realizada entre 2004 e 2005 com o apoio financeiro do CNPq e parceria institucional da TVE/Rede Brasil. O estudo tinha como objetivo central descrever e analisar as relações que as crianças estabelecem com o que vêem na televisão, e compreender o modo como elas lidam com os conteúdos dos produtos televisivos aos quais têm acesso cotidianamente. Interessava-nos também perceber como identificam valores presentes nos produtos televisivos e como articulam esses valores aos que elas constroem na interação com outros espaços de socialização como família, escola, grupo de pares etc.

Em nossos estudos, partimos do pressuposto de que a mídia é um processo institucionalizado, em que diferentes atores se reúnem e se confrontam, buscan-

* Estudo realizado pelo Grupo de Pesquisa em Educação e Mídia (GRUPEM), ligado ao Programa de Pós-Graduação em Educação da PUC-Rio. do alcançar alguma síntese de significados, ainda que provisória. Nesse processo, o sentido das mensagens não é construído de forma unidirecional - da mídia para o sujeito -, mas na relação entre o universo particular do sujeito e os produtos da mídia. Entendemos que o receptor não é passivo, ele participa da produção de sentido dentro de uma lógica cultural e lida com as possibilidades que essa cultura lhe abre (ou limita) para construir significados.

O paradigma que descreve a comunicação como processo linear unidirecional: fonte $\longrightarrow$ emissor $\longrightarrow$ estímulo $\longrightarrow$ telespectador $\longrightarrow$ efeito, no qual o espectador é visto como receptáculo inerte, passivo e vazio, psicológica e culturalmente, foi superado pelo paradigma da bidirecionalidade. De acordo com Fuenzalida (2002), a tese da passividade perceptiva do espectador sustentou-se teoricamente, durante muitos anos, no behaviorismo, na epistemologia marxista e no althusserianismo; este último concebia os meios de comunicação exclusivamente como aparelhos ideológicos do Estado, expressão que, segundo o autor, era uma metáfora das "máquinas da Revolução Industrial atuando fisicamente sobre os recepto- 
res, concebidos como objetos manipuláveis" (p. 22). Nessa perspectiva, "o emissor manejaria capacidades onipotentes, a partir de suas mensagens, para produzir efeitos (publicitários, comportamentais, ideológicos, políticos, educativos etc.) nos indefesos e passivos televidentes" (idem, ibidem).

A maioria dos atuais teóricos da recepção questiona esse modelo e, mesmo reconhecendo o poder de convencimento das mídias, procura resgatar os modos de réplica do espectador. Segundo MartinBarbero (2004), esse resgate "desloca o processo de decodificação do campo da comunicação, com seus canais, seus meios e suas mensagens, para o campo da cultura, dos conflitos entre a cultura e a hegemonia" (p. 127) e não implica, em absoluto, fechar os olhos para o poder dos meios.

Silverstone (1994) adverte que, antes de fazer afirmações contundentes e sem base empírica a respeito da ação implacável da televisão sobre espectadores incapazes de resistir ao poder dela, é preciso investigar em que circunstâncias, como, com que mecanismos e através de que processos se dá a atividade da audiência (p. 259). Mesmo que não se possa afirmar uma completa autonomia do telespectador em relação ao conteúdo da televisão, pode-se, com certeza, supor que não haja, do lado de cá da tela, apenas uma massa de modelar na qual se imprimem coisas ou indivíduos incapazes de construir suas próprias opiniões a respeito do que vêem. Além das contradições e ambigüidades que atravessam os meios de comunicação, eles próprios arenas de luta em que diferentes posições se confrontam, com maior ou menor legitimidade, do lado de fora dessas megaestruturas também existem sujeitos inteligentes, capazes de dialogar, de forma mais ou menos criativa, com os enunciados que lhes são dirigidos, e de refletir, com diferentes níveis de criticidade, sobre o conteúdo e significado das mensagens a que têm acesso.

Nossas investigações têm na tese da audiência ativa uma de suas referências, e partem do pressuposto de que, por mais eficientes que sejam as estratégias das mídias para seduzir e "conduzir" os receptores, estes estabelecem relações ativas com os textos ou mensagens da comunicação. Sabemos que os textos midiáticos, como enunciados construídos a partir de um determinado ponto de vista, são intrinsecamente carregados de sentido e servem a propósitos e interesses políticos, financeiros e ideológicos, produzindo marcas na relação audiência-televisão, e isso nos impede de supor a existência de uma audiência totalmente livre, que produz sentidos sem restrições. Como adverte Bailén (2002):

[...] el telespectador no es autónomo a la hora de decidir qué espacio consumir. Siempre, en última instancia, es la televisión la que ejerce la autoridad sobre el que mira, al determinar la oferta y establecer las modas pragmáticas. Las finalidades y contenidos no están bajo el control de la audiencia. (p. 171)

Mas temos como contra-argumento a tese de que os textos, quaisquer que sejam, embora limitem e orientem as leituras e interpretações que se pode fazer deles, não as conformam e não as controlam, pois há sempre um espaço em que o leitor pode, por si mesmo e a partir de seus pressupostos, interpretar o que lê. Se isso é verdadeiro no que se refere a textos escritos, por que não o seria também no caso do texto audiovisual? Por que atribuir à linguagem audiovisual poderes superiores aos que ela de fato tem?

Para Silverstone (1994), falar em audiência ativa chega a ser uma redundância, pois há sempre algum nível de atividade na relação que estabelecemos com o que vemos e ouvimos. Assim, a tarefa dos pesquisadores de processos de recepção é definir a dimensão, o significado e os limites dessa atividade, nos diferentes contextos em que se processa o ato de espectatura. ${ }^{1}$ Segundo Fuenzalida (2002), um espectador ativo não tem necessariamente de estar atento e concentrado, refletindo profundamente sobre o que

\footnotetext{
1 Ato de espectatura (l'acte de spectature) é um conceito
} desenvolvido pelo semiótico canadense Martin Lefebvre (1997), em substituição ao conceito de leitura, para pensar a relação que o espectador estabelece com o produto audiovisual. 
está vendo: a audiência outorga aos televisores ligados em casa uma atenção variável, que pode ser concentrada em alguns programas, pode ser mais auditiva que visual em outros e pode ser completamente distraída nos momentos em que o telespectador olha o televisor de passagem, apenas para tomar ciência do que está sendo exibido.

Esta "atividade" não é criativa ou racional o tempo todo, e nem tem de ser: "pode referir-se a uma leitura criativa [...], mas pode também se referir ao processo mais trivial de fazer encaixar o texto em marcos ou hábitos familiares" (Livingstone apud Silverstone, 1994, p. 253, tradução livre). Reconhecer que há atividade em diferentes graus na relação com a televisão não significa afirmar uma total autonomia do espectador (mesmo porque não se pode falar em autonomia absoluta em nenhuma instância da vida social). Não é preciso negar a atração exercida pela linguagem televisiva, nem, muito menos, subestimar sua capacidade de difundir ideologias e criar comportamentos para admitir que os telespectadores são sujeitos que pensam e que podem adotar formas mais ou menos criativas de lidar com o que vêem, o que não significa, em nenhuma medida, passividade. Segundo Silverstone,

Podemos afirmar que la práctica de mirar televisión es activa en tanto incluye alguna forma de acción más o menos provista de sentido (incluso en su modo más habitual o ritual). En este sentido, no existe la práctica pasiva de ver televisión [...]. Podemos afirmar que ver televisión ofrece diferentes cosas, diferentes experiencias, a diferentes espectadores. Pero reconocer que la diferencia carece de toda utilidad si no somos capaces de especificar las bases de esas diferencias. (1994, p. 255)

Os estudos de recepção realizados nos últimos vinte anos, em diferentes países, ${ }^{2}$ documentam a capacidade das audiências de discriminar e produzir senti-

2 Livingstone (2003, Inglaterra), Martin-Barbero (2001, 2002, 2003, 2004, Colômbia), Orozco Gómez (1991, México), Silverstone (1994, Inglaterra), Bailén (2002, Espanha), entre outros. dos a partir do tipo de consumo que fazem da televisão, sentidos estes que são transformados e/ou negociados, e são, todo o tempo, mediados por diferentes instâncias (escola, família, grupo de pares, igreja etc.). Esses estudos inspiram as pesquisas que o GRUPEM vem realizando na área de educação desde 2001, tendo como objetivo analisar, descrever e compreender:

a) como crianças e jovens dão sentido ao conteúdo dos produtos audiovisuais aos quais têm acesso regular;

b) como se estruturam os esquemas de significação de que fazem uso para se apropriar do conteúdo desses produtos;

c) como percebem valores veiculados ali e como os articulam aos seus pressupostos;

d) como a produção audiovisual participa da construção de suas identidades (culturais, sociais, sexuais, de gênero).

Nossos estudos pretendem integrar-se ao esforço coletivo e cumulativo da produção teórica em torno das relações entre mídia e educação, investigando as relações que crianças e jovens estabelecem com a televisão, o cinema e a internet.

Partimos do pressuposto de que estamos lidando com um fenômeno complexo, instável e de difícil apreensão empírica - a produção de significados em torno de produtos audiovisuais e a relação entre esse processo e a construção de valores - e que analisá-lo, descrevê-lo e compreendê-lo exige a adoção de parâmetros investigativos distintos dos tradicionalmente utilizados nas pesquisas educacionais. "Para conocer mejor al telespectador, seria muy útil continuar avanzando en el diseño de nuevas técnicas cualitativas", afirma Bailén (2002, p. 171). Entendemos que a melhor forma de investigar as relações que os espectadores estabelecem com os produtos audiovisuais é perguntando a eles o que pensam sobre o que vêem. Desse modo, questões que dizem respeito a como crianças e jovens percebem e analisam o que assistem na televisão, que entendimento têm das mensagens, informações e valores ali veiculados, são colo- 
cadas para eles, e suas respostas, dadas oralmente ou por outros meios de expressão (textos escritos, desenhos, animações, esquetes, brincadeiras), constituem o eixo central de nossas pesquisas.

\section{A pesquisa}

Pela dimensão da audiência infantil da televisão brasileira, optamos por um estudo de base quantitativa, buscando coletar dados junto a um significativo número de sujeitos que nos permitisse traçar um panorama geral da relação entre crianças e televisão. Inspirados em um modelo de investigação desenvolvido pelo Fundo das Nações Unidas para a Infância (UNICEF) em outros países, intitulado "TV como te quiero", ${ }^{3}$ optamos por fazer uma chamada pela televisão convidando crianças a participarem da pesquisa enviando-nos suas opiniões sobre a televisão. Tratava-se de realizar um estudo de menor amplitude, com objetivos distintos dos que orientaram o projeto "TV como te quiero", mas cujos dados pudessem ser cotejados com aqueles, no intuito de estabelecer algumas comparações entre crianças brasileiras e crianças de outros países. Decidimos manter a chamada pela televisão, veiculando-a apenas em âmbito regional e somente através de emissoras de televisão públicas, que atingem um público menor e mais específico de crianças. A TVE/Rede Brasil garantiu a produção e veiculação do $s p o t,{ }^{4}$ cuja concepção, roteiro e direção ficaram a cargo da equipe de pesquisa (sob a coordenação de um de seus membros, que é roteirista e diretor de televisão). Decidimos também ampliar a pergunta dirigida às crianças, que passou a ser: "O que eu penso da tevê".

Nossa intenção era coletar um material que nos possibilitasse abarcar não apenas as expectativas das

3 Na Argentina, no Chile e Uruguai a pesquisa foi coordenada pela socióloga argentina Tatiana Merlo Flores. Um dos relatos de resultados obtidos encontra-se publicado com o título "A imagem como símbolo cultural”, no livro organizado por Porto (2003).

4 Peça audiovisual de curta duração, semelhante a um filme comercial, inserida nos intervalos da programação. crianças com relação à TV, mas, mais diretamente, a relação que elas estabelecem com o que vêem regularmente, incluindo gostos, interesses, críticas e grau de conhecimento da linguagem e dos formatos televisivos. O spot convidava crianças da Região Sudeste, com idades entre 8 e 12 anos, a enviar cartas, desenhos ou mensagens eletrônicas para o grupo de pesquisa, com suas reflexões a respeito do que viam na televisão, do que gostam e do que não gostam de ver e por quê. Para garantir um maior número de respostas, decidimos envolver também os professores na campanha: mandamos confeccionar cartazes dirigidos a eles, solicitando-lhes que estimulassem seus alunos a participar da pesquisa. Os cartazes foram encartados no jornal Folha Dirigida.

Recebemos mais de 900 respostas, entre desenhos e textos. Todo o material foi catalogado e identificado. Os textos, digitados e fragmentados em unidades de significação (como no exemplo abaixo), configuram a principal fonte de dados da pesquisa.

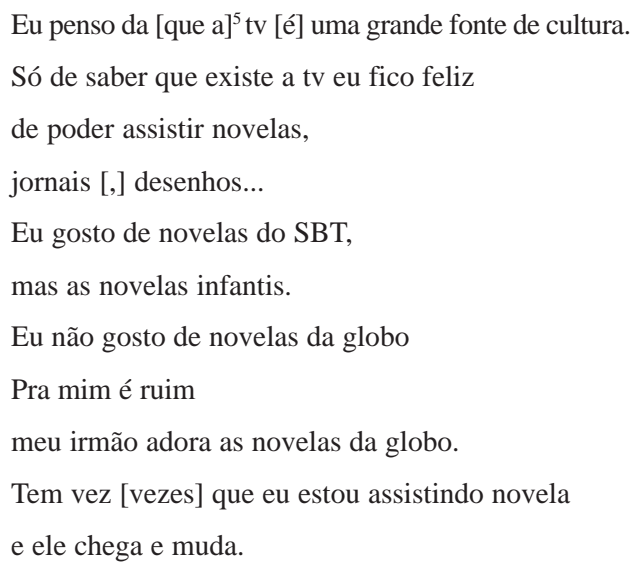

5 As correções ortográficas e gramaticais foram feitas entre colchetes para não alterar o texto da criança. 
Todos os textos foram analisados por todos os membros do grupo de pesquisa, a partir de categorias teóricas (definidas previamente a partir da literatura de referência), e categorias não-teóricas (extraídas da primeira leitura dos textos). Isso permitiu a organização das informações, idéias, opiniões e reflexões expressas pelas crianças a respeito dos diferentes canais de televisão a que têm acesso; dos seus programas prediletos; da violência presente nos produtos televisivos; do papel desempenhado pela televisão no seu cotidiano; das concepções delas acerca da influência da televisão na sociedade, além de temáticas mais gerais, como consumo e qualidade da produção televisiva.

Os textos foram "vasculhados", um a um e em conjunto, utilizando um programa de análise de dados qualitativos; desse modo, os fragmentos eram "retirados" de suas respectivas origens (textos originais) e reagrupados por eixos temáticos (violência na televisão, consumo, representações iconográficas da televisão, desenhos animados japoneses, telenovelas, telejornais, o vício de ver televisão).

\section{Perfil geral das crianças}

Participaram desta pesquisa 986 crianças; $56,1 \%$ delas estavam em escolas públicas e 43,9\% em escolas particulares; a maioria $(66,8 \%)$ tinha, na época, entre 9 e 11 anos, como indica o gráfico abaixo:

Figura 1 - Idade da criança

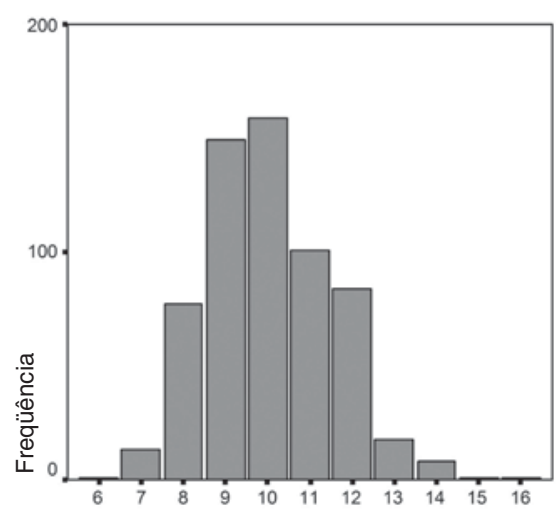

Quanto ao gênero, $46 \%$ são meninos e $54 \%$, meninas. Quanto à origem das respostas, 59,8\% vie- ram de Minas Gerais, 34,8\% do Rio de Janeiro e 4,5\% de São Paulo, como mostra a figura abaixo:

Figura 2 - Estado

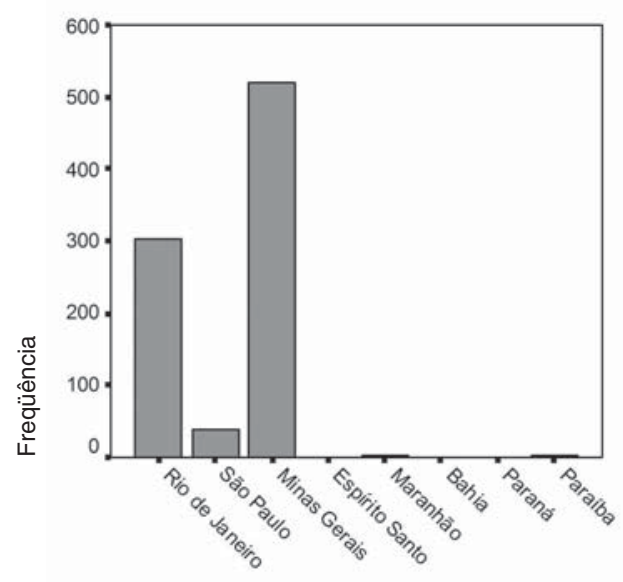

\section{Ensinagem, ou o que as crianças pensam sobre o que elas aprendem com a tevê}

Este eixo temático foi privilegiado neste texto em função da importância do tema para a área de educação. "Televisão não é só diversão, é também informação e ensinagem". Essa frase, escrita por uma menina de 10 anos, expressa, de forma emblemática, uma temática recorrente nos textos que recebemos. Para essas crianças, a educação é uma das principais atribuições da TV, mas não vem sendo cumprida muito bem, como se pode observar nas frases abaixo:

- A tevê devia parar de mostrar coisas tão "bobas".

- A tevê devia ter programas com o objetivo de fazer as pessoas pararem e refletirem, tipo umas brincadeiras fazendo as pessoas aprender.

- Podia inventar um programa para dar educação para todas as crianças e para os adultos também. ${ }^{6}$

Certamente, em boa parte dos textos das crianças há ecos da opinião dos adultos a respeito dessa

6 Fragmentos de textos de crianças de várias idades, que freqüentam escolas diferentes em cidades diferentes. 
questão, sobretudo quando elas se referem a uma televisão do passado, supostamente mais educativa e menos boba do que a atual, como na frase "a televisão hoje em dia não passa mais programas educativos". Mas esse não é o eixo central dos textos delas. O modo como as frases são formuladas e o contexto em que aparecem - sempre articuladas a uma longa série de elogios ao que a televisão tem de bom e ao que elas gostam de ver, além das numerosas sugestões quanto ao que deveria ser exibido - indicam que essas crianças expressam sua própria opinião a respeito do que é e do que não é educativo na televisão, e que, mesmo gostando muito de ver televisão, esperam mais da programação televisiva do que o que está sendo oferecido no momento.

Muitas crianças fazem questão de assinalar que estão enganados os que pensam que apenas os canais "educativos" têm a prerrogativa de ensinar. Reproduzindo, intuitivamente, uma frase repetida muitas vezes por Orozco Gómez, ${ }^{7}$ elas afirmam que é possível aprender muitas coisas com a televisão porque "todos os canais ensinam um pouco", embora de forma diferente uns dos outros. Afirmam que a televisão ensina "coisas boas", tais como "lavar as mãos; não falar com estranhos; cuidar das plantas", e que, através dela, as crianças podem ter acesso a informações sobre a vida, sobre o mundo, sobre outros lugares e pessoas e também sobre "coisas que servem para a escola". Mas reconhecem que nem tudo o que a televisão ensina é bom, porque há canais e programas que ensinam "muitas coisas que não prestam", coisas que "prejudicam as crianças" e que "não deveriam ser ensinadas, coisas ruins" como "roubar, matar, assassinar, usar drogas, brigas e desobedecer os pais".

A análise descritiva dos mais de 400 textos que recebemos usou como parâmetro para organizar e interpretar seu conteúdo tanto palavras e expressões que as crianças utilizam para explicar a relação que man-

7 No texto de abertura do livro Televisión, audiencias y educación, Guillermo Orozco Gómez (2001, p. 6) utiliza uma frase exatamente igual. têm com a televisão quanto categorias definidas pela equipe a partir de uma leitura exploratória do material, realizada em conjunto. Para descrever com alguma precisão o sentido atribuído por elas ao que consideram "o lado bom da tevê", priorizamos três categorias:

a) coisas boas da televisão: classificação utilizada pelas crianças, que engloba o que consideram agradável, divertido, importante e interessante no conteúdo do que vêem;

b) coisas práticas: categoria adotada por nós para classificar os aprendizados descritos pelas crianças como úteis para a vida prática, pois estão relacionadas com atividades do cotidiano, regras de convívio social e hábitos de higiene;

c) educativo: o que, segundo as crianças, é intrínseco aos canais educativos, mas está presente também nos outros canais e diz respeito especificamente às coisas que as crianças precisam saber, habilidades que precisam desenvolver para ser alguém na vida ou vir a ser adulto, além de informações que servem para a escola.

Entre o que as crianças classificam, genericamente, como fazendo parte das "coisas boas da televisão" ou do "lado bom da tevê" encontram-se, fundamentalmente, os desenhos animados, os telejornais e os programas educativos, além de:

- coisas que você acha muito legais, que nem futebol, judô, andar de skate, jogar tênis e preservar a natureza;

- ensinar as crianças pequenas muitas coisas boas como: contar, cantar e ficar esperto do pensamento;

- ensinar conquistas e vitórias do dia-a-dia;

- fazer chorar e sorrir, ensinar a conviver com as pessoas e a ajudar as pessoas.

Para algumas crianças, a televisão é boa principalmente porque "nos faz raciocinar mais rápido" e "nos faz ficar inteligentes". Essa opinião aparece em 
textos e está presente também em alguns dos desenhos que recebemos, como este que reproduzimos abaixo:

\section{Figura 3}

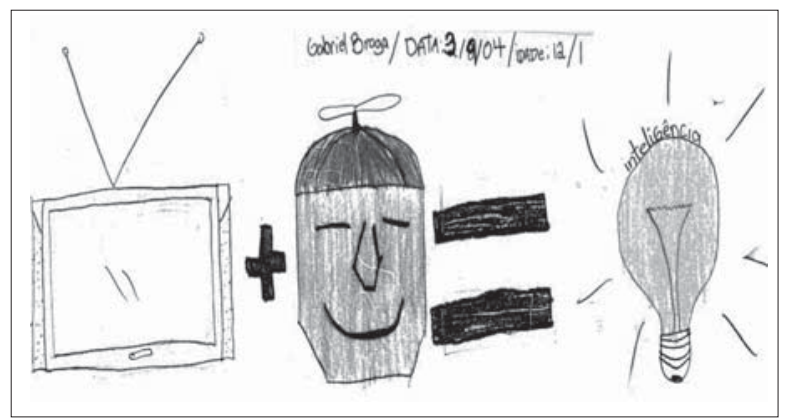

Aqui, Gabriel, um menino de 12 anos, apresenta uma equação matemática que pode ser descrita como: televisão mais cabeça de criança (o chapéu colorido com hélice sugere que se trata de uma criança) igual a idéia inteligente ou inteligência, como está escrito no alto da lâmpada (nas histórias em quadrinhos a lâmpada é ícone tradicionalmente utilizado para representar boas idéias). Afirmações como essa estão fundadas na crença, mais ou menos comum, de que inteligência é o mesmo que acúmulo de informações, que sustenta, por exemplo, opiniões populares a respeito dos Quiz Show e de seus vencedores. ${ }^{8}$

Em países como o Brasil, no qual o ingresso dos setores populares na Modernidade não se deu através dos livros, mas, fundamentalmente, pela ação do rádio e da televisão, é de certa forma compreensível que sejam atribuídos à televisão méritos relativos à ampliação da inteligência, já que foi por meio dela que informações acessíveis apenas aos alfabetizados chegaram às grandes massas.

Para Martin-Barbero (2001), a aversão que os intelectuais têm aos produtos televisivos, que os leva a classificá-los em bloco como "incultura", assenta-

8 Por mais paradoxal que seja, este parece ser também o pressuposto subjacente à tese defendida por uma certa elite intelectual para quem televisão "emburrece”, justamente porque não informa. se em pré-conceitos segundo os quais as mídias que falam mais à emoção do que à racionalidade nada acrescentam à vida intelectual, apenas idiotizam e limitam a atividade do pensamento. ${ }^{9}$ Discordando dessa concepção, o autor lembra que a televisão "ocupa um lugar estratégico na dinâmica da cultura cotidiana das maiorias, na transformação das sensibilidades, nos modos de construir imaginários e identidades" (p. 26), e desqualificar o papel que ela desempenha nesse contexto é desqualificar também processos instituintes de matrizes culturais permanentes.

As crianças que participaram desta pesquisa têm críticas aos produtos de má qualidade exibidos pela televisão, mas estão seguras de que o papel que ela cumpre na difusão de idéias e informações (para elas, muitas vezes associado à ampliação da inteligência) supera e compensa seus equívocos.

Além das "coisas boas" que a televisão ensina, podem ser identificadas nos textos das crianças "coisas boas para a vida prática ou para o convívio social", presentes em frases como as que se seguem, entre outras:

- A televisão é ótima porque ela nos ensina a não falar com estranhos, a não aceitar certas coisas como balas, pirulitos, chocolates, porque podem conter drogas, a não sair sozinha, ir acompanhada com um adulto conhecido etc.

- A tevê ensina como cuidar dos alimentos, como cuidar das plantas, que tem que regar as plantas todos os dias.

- ensina coisas sobre venda de carros e acessórios, coisas que servem para a experiência de algo, usar camisinha e não engravidar cedo.

- A televisão tira nossas dúvidas, por isso sabemos que o presidente do Brasil é Lula, que o governador é Aécio Neves e muito mais; ela nos informa o que está acontecendo no mundo, ficamos sabendo das notícias do Brasil e outros países, ajuda a compreender como é a realidade de outras crianças.

9 O cinema inibe a atividade intelectual do espectador, diziam Adorno e Horkheimer em 1947 (Adorno e Horkheimer, 1985). 
- Com ela podemos participar de maneira figurada de tudo o que acontece no mundo.

As crianças dizem que todos os canais ensinam um pouco, mas reconhecem a especificidade dos canais "educativos" como os que têm a função precípua de ensinar e o fazem de forma muito mais eficiente e correta:

- O canal Cultura é para ensinar as crianças.

- No canal da Cultura, tem muitos desenhos legais que ensinam as crianças.

- Tem canais que não são tão violentos e ensinam, por exemplo, o canal 2 [TVE Rede Brasil].

- Os canais que me ensinam certas coisas são: Discovery Kids, National Geografic Channel.

Elas classificam também como conteúdos educativos: "as partes do corpo humano"; "preservar a natureza"; "coisas de ortografia, história, geografia, ciências"; "ensinar sobre os bichos, desenhos, lendas"; "programas que servem para as crianças aprenderem mais sobre natureza"; "que podem nos ajudar na escola". Além disso, para elas os canais educativos ensinam melhor porque veiculam "programas com menos violências".

Os telejornais também são citados entre as "vantagens" e os "lados bons" da televisão, pois as crianças os identificam com a possibilidade de acesso a informações e ao conhecimento da "realidade": "seus lados bons [da tevê] são que recebemos informações através dela". Mesmo quando afirmam que os jornais são muito chatos e representam aquilo que não gostam na televisão, porque "só falam de coisas tristes e só trazem notícias ruins", ainda assim declaram acreditar que eles são necessários porque "nos mantém informados sobre o que está ocorrendo no mundo".

Uma considerável parcela atribui um grande valor à informação. Não é possível saber se de fato elas percebem que este é um "capital” necessário para viver nesta sociedade ou se reproduzem a opinião dos adultos a esse respeito, mas é recorrente nos textos delas a idéia de que é muito importante "estar infor- mado sobre o que está ocorrendo no mundo, ficar sabendo das notícias do Brasil e outros países, compreender como é a realidade de outras crianças para participar de maneira figurada de tudo o que acontece no mundo" (menina, 10 anos).

Elas acreditam que a televisão é fonte quase exclusiva de certas informações que precisam ter, como indica a frase a seguir, escrita por um menino de 11 anos: "A televisão é o tipo de coisa que serve também para você ficar sabendo de muitas notícias. Por isso, é preciso ter uma televisão em casa, porque você não vai poder saber das notícias".

Um outro menino diz que gosta do telejornal, "pois com ele nós nos inteiramos dos acontecimentos mundiais e nos tornamos mais cultos e inteligentes".

A maioria critica as emissoras de televisão por não cumprirem de forma séria e competente a tarefa de ensinar às crianças o que elas precisam saber para viver em sociedade, como escreve um menino de 12 anos de uma escola particular da zona oeste do Rio de Janeiro: "na televisão há poucas coisas que nos ensinam a viver; a televisão não pode ensinar coisas erradas, pois assim, só vai estar piorando na 'construção' do futuro; a televisão atinge milhões de pessoas, por isso ela tem que saber que não pode ensinar coisas erradas".

\section{O que as crianças pensam sobre o modo como a tevê ensina e o modo como se aprende com ela}

As crianças levantam hipóteses bastante interessantes a respeito do modo como as pessoas aprendem com a televisão, demonstrando o quanto estão atentas aos debates que são travados a esse respeito. $\mathrm{O}$ conteúdo dos textos sugere que elas pensam que a televisão ensina mostrando, isto é, que mostrar é o mesmo que ensinar; elas afirmam que quando a televisão mostra algo, está necessariamente incentivando (expressão muito utilizada por elas nos textos) os espectadores a imitar (expressão também recorrente) o que está sendo mostrado. Mesmo que se trate de uma denúncia ou de um alerta, por exemplo. Assim, para alguns, quando uma novela insere em sua trama 
um personagem que faz uso de drogas ou de álcool, está incentivando os espectadores a fazer o mesmo (mesmo que essa inclusão seja para alertar o público para os perigos decorrentes dessa prática, como no caso do merchandising social). É dessa perspectiva que criticam os telejornais que, na opinião delas, ao mostrarem crimes, prostituição e abuso sexual de crianças, estimulariam os espectadores "menos preparados" a praticarem atos semelhantes. Isso pode ser identificado nas frases que se seguem, extraídas de textos de crianças diferentes:

- Na novela tinha um personagem que batia na mulher de raquete porque tinha muito ciúme dela. Eu acho que isso não dá educação, senão os homens não vão mais respeitar as mulheres. ${ }^{10}$

- Tem canais que nos ensinam a matar e a não obedecer os pais.

- A violência na televisão nos ensina a matar e assassinar. Como no Canal 5, alguns filmes com muita violência, homem batendo em mulher, assassinando e matando.

- Na tevê tem muita violência, tem mortes, assaltos, seqüestros, tiroteio e brigas. Assaltam os comércios. Os bancos e as casas. Eles roubam carros, caminhões etc. E ensinam as pessoas a roubar e matar. Incentivam as pessoas a roubar, a cheirar, a matar e beber.

- Eu não gosto de novelas que ensinam fumar, assaltos crimes e etc.

Guardadas as devidas proporções, essa concepção aproxima-se muito de certas concepções acadêmicas sobre os efeitos da televisão, que advogam que a simples exibição de imagens de violência por si só incitaria os telespectadores a à violência, independentemente do contexto em que elas aparecem ou dos

${ }^{10}$ Vale mencionar que esses personagens foram incluídos na trama da novela Mulheres apaixonadas (Rede Globo, 2003/ 2004) com o intuito de protagonizarem uma campanha educativa (merchandising social) que tinha como objetivo denunciar a violência contra a mulher. significados atribuídos a elas no contexto narrativo em que estão inscritas.

No entanto, entre as crianças que participaram desta pesquisa, a maioria das que acham que mostrar é o mesmo que ensinar a fazer igual acredita que nem todos os telespectadores imitam o que é mostrado, isto é, que nem todos se deixam influenciar pelo conteúdo do que é exibido pela televisão. Acham que, mesmo quando ensina o que é errado, a televisão não faz mal aos que sabem diferenciar o que deve do que não deve ser imitado, aos que sabem, como elas, escolher "o melhor caminho a seguir". Para essas crianças, os influenciáveis são adolescentes e adultos que não entendem bem o sentido do que está sendo mostrado, e também as crianças pequenas:

- Quando os jornais mostram sobre as drogas, sobre roubos, mesmo em um bom sentido, eu acho que na mente de algumas pessoas, elas pensam errado, pois elas tiram idéias para fazer o mesmo.

- ATV influencia muitas coisas, principalmente as novelas. As pessoas ficam viciadas em tudo que se fala, em todos os comerciais, e tentam ficar iguais às atrizes.

- [As novelas] fazem também propaganda do silicone e botox que eles acham que é moda, mas, na verdade, são uma grande droga. As mulheres botam silicone, tentam se aperfeiçoar e acabam estragando a beleza própria.

- Uma vez apareceu na televisão um tênis e um homem voando com esse tênis, um menino de 4 anos comprou o tênis e pulou da sacada pensando que o tênis voava; resultado: me parece que ele morreu.

Essa visão parece reproduzir, intuitivamente, uma perspectiva defendida no meio acadêmico, que costumamos chamar, ironicamente, de tese dos "grupos de risco" (Alegria \& Duarte, 2005). Segundo os defensores desta tese, haveria na sociedade grupos sociais intrinsecamente mais vulneráveis que outros aos efeitos negativos da televisão, entre os quais figuram os pobres e/ou analfabetos e/ou adultos menos escolarizados, além de crianças, adolescentes e, muitas vezes, mulheres. Nessa perspectiva, apenas os intelectuais ou adultos com escolaridade elevada e os jo- 
vens politizados estariam fora dos chamados grupos de risco e seriam, talvez, os únicos grupos sociais a não se deixarem enganar e seduzir pela magia manipuladora das mídias.

A inesperada proximidade da fala de crianças com opiniões emitidas no meio acadêmico pode estar refletindo a ausência de dados científicos consistentes em torno do problema. Na verdade, pesquisas realizadas em todo o mundo, nos últimos trinta anos, acerca dos possíveis efeitos da televisão sobre seus telespectadores, ainda não produziram dados consistentes o bastante para permitir afirmações desse tipo, o que faz com que boa parte das opiniões a esse respeito esteja ancorada em pré-conceitos e concepções do senso comum, o que indica que há ainda muito a ser feito nesse campo.

\section{Valores, o principal aprendizado}

A maior parte do que as crianças dizem que aprendem com a televisão diz respeito a valores, isto é, concepções normativas de conduta que atravessam de forma mais ou menos explícita certos programas da grade televisiva, especialmente novelas e desenhos animados japoneses. Para as crianças, esses programas mostram como é "a realidade da vida" e, fazendo isso, orientam-nas a agir em sociedade e "ensinam o que há de bom e de mal no mundo e nas pessoas. $\mathrm{O}$ programa que eu mais gosto é Malhação", diz uma menina de 12 anos, "porque fala de tudo um pouco: de drogas, escola, escolhas da vida, namoros...". Outra menina acha que é importante ver Malhação porque mostra a vida dos adolescentes e prepara as crianças para o futuro.

Uma criança afirma que novelas incentivam "a rebeldia de filhos contra os pais"; outra, que elas "nos ensinam a ser bons para no futuro ser uma boa pessoa"; para uma terceira, "as novelas induzem as pessoas à violência, ao sexo e a agressões físicas contra os filhos". Para um menino de 11 anos, "Senhora do destino [novela que estava sendo exibida quando a pesquisa foi realizada] ensina as pessoas a lutar para ser alguém na vida e ter justiça". Várias crianças di- zem que "Há novelas que mostram sempre o mal vencendo o bem, sem que nunca se mostre a realidade", enquanto outras afirmam que elas "ensinam a respeitar a família e a amar".

No que diz respeito aos desenhos animados japoneses, um menino de 10 anos diz que aprende com eles a ser "honesto e humilde"; outro diz que esses são os seus programas favoritos porque "ensinam o certo e o errado".

Segundo o pedagogo catalão Josep Maria Puig (1998), valores são conceitos relativamente abstratos que só se efetivam como referenciais práticos de conduta, como mapa que norteia a vida social, quando são problematizados nas experiências vividas por nós no interior de campos de problematização moral. Para esse autor, "campos de problematização moral são, simultaneamente, espaços de reflexão e ação moral nos quais se produz certa quantidade de saber normativo ou de guias de valor que norteiam o comportamento de cada um dos sujeitos e de todos conjuntamente" (p. 171). Nesses espaços apresentam-se as temáticas em torno das quais a sociedade "levanta problemas, transmite a seus membros reflexões morais referentes a tais dificuldades e sugere valores e caminhos que apontam a superação dos dilemas colocados" (idem, ibidem).

Em sociedades como a nossa, as mídias atuam como campo de problematização moral, participando da construção e veiculação de guias de valor, definidos por Puig (1998) como produtos culturais ou realidades informativo-significativas que modelam e orientam as formas de vida e a convivência dos indivíduos e grupos em uma dada sociedade. No entanto, ao contrário do que se pensa, a atuação das mídias nesse processo não é mais poderosa do que a dos demais espaços de mesma natureza, pois, embora sejam apresentados de forma mais atraente e sedutora, os guias de valor veiculados em narrativas televisivas (ficcionais ou não) são os mesmos que circulam pelas demais instâncias da sociedade. Além disso, guias de valor refletem uma cultura moral global e coerente, mas nunca homogênea, pois se trata de "uma cultura que permite usar de modo singularizado alguns de seus 
elementos e recusar outros" (p. 196), conferindo à liberdade um campo de possibilidades delimitado e compreensível, mas, ainda assim, de escolhas.

As crianças percebem que a televisão coloca para os telespectadores questões relacionadas ao comportamento moral. Para elas, a televisão tanto ensina a fazer o certo quanto o errado, ensina a ser justo e também a ser cruel, mostra o bem e o mal, "ensina a ter educação e a ter respeito pelos mais velhos", e, ao mesmo tempo, "influencia muito a violência". Elas dão-se conta das contradições internas do veículo e sinalizam isso em seus textos: "Dentro dos programas tem coisa legal, mas depois passa a violência, e assim vai”.

É recorrente também a afirmação de que nem tudo que a televisão ensina, de bom ou de ruim, é aprendido. A maioria das crianças faz a defesa da tese de que a escolha do que se aprende ou não se aprende com a televisão cabe sempre ao telespectador: "a televisão estimula tanto o crescimento quanto a destruição, você é que escolhe", escreve uma menina de 12 anos de uma escola pública de Minas Gerais.

\section{Considerações finais}

Resultados muito semelhantes aos que obtivemos em nosso estudo foram relatados por Greenberg, em 1976 (apud Galera, 2000), na Inglaterra, e diziam respeito a crianças de faixa etária semelhante a das que nos escreveram. Naquela ocasião, as crianças entrevistadas pelo pesquisador disseram que buscavam a televisão como meio de aprendizagem, porque esta lhes possibilitava:“1) aprender o que acontece no mundo; 2) aprender sobre coisas que tenham sido explicadas no colégio; 3) aprender como se deve atuar em determinadas circunstâncias; 4) aprender o que pode acontecer com elas e 5) ver como outras pessoas resolvem seus próprios problemas" (p. 66).

Ambos os estudos sugerem que as crianças não têm dúvidas quanto ao caráter educativo da televisão e que elas parecem saber avaliar o que a televisão pode ou não lhes oferecer do conjunto dos saberes que acreditam serem necessários para transitar na sociedade. Apesar das duras críticas que os adultos, so- bretudo os educadores, fazem à televisão, as crianças, segmento mais significativo de telespectadores na maioria dos países do mundo, a têm em alta conta porque, na opinião delas, ela consegue aliar "ensinagem" e "entretenimento". Elas sabem que nem tudo que é educativo pode ser ensinado de forma divertida, mas indicam, em suas falas, que a televisão lhes oferece a chance de ter acesso aos conhecimentos de que precisam para terem "um belo futuro pela frente", de maneira agradável, atraente e interessante. Isso é o que vêm buscando, com sucesso, numerosos museus de ciência pelo mundo afora. ${ }^{11}$

Vale assinalar que a opinião infantil sobre um tema que lhe é caro não se fundamenta em uma percepção acrítica ou ingênua do veículo. É verdade que muitas crianças atribuem um valor intrinsecamente positivo à programação televisiva, como indica o texto de um menino de 12 anos, de uma escola pública de Araguari, Minas Gerais:

Nos dias de hoje a televisão vem de todos os cantos do mundo, trazendo educação, cultura de outros países, costumes de diferentes povos. A televisão traz conhecimento de todos os lugares. As pessoas aprendem muito com a televisão, tudo que acontece no dia os telejornais passam as informações para as pessoas terem conhecimento de tudo que aconteceu naquele dia. Existe [existem] vários programas na televisão [em] que as pessoas podem aprender muitas coisas, existe [existem] também os programas de lazer como futebol e novelas que também nos passam muita informação. Quase todas as pessoas já tem [têm] televisão em casa, por isso elas [se] tornam mais cultas e informada [informadas].

${ }^{11}$ Em palestra proferida na $4^{\mathrm{a}}$ Cúpula de Mídia para Crianças e Adolescentes, o pesquisador mexicano Guillermo Orozco Gómez apresentou aos participantes imagens de seu mais recente projeto mídia-educativo: a reestruturação do Museu de Ciências de Guadalajara (México), incorporando recursos audiovisuais digitais para que as crianças pudessem utilizar todos os equipamentos de forma totalmente interativa. Essa é também a estratégia utilizada por numerosos museus de ciência em todo o mundo. 
Mas, em contrapartida, outras tantas crianças se dizem preocupadas com os equívocos da televisão, sobretudo o excesso de imagens de violência e o que consideram "maus exemplos" na televisão, como indicam os textos transcritos abaixo, de um menino e de uma menina de uma escola pública de São Gonçalo, Rio de Janeiro:

O programa que eu não gosto de assistir é o filme Cidade de Deus, porque mostra muita coisa que é ruim para a vida de uma pessoa, mostra muita violência e as pessoa [pessoas] fumando maconha, mostra armas, brigas, e tem mais um programa que eu não gosto de ver, é o Linha Direta [que] mostra confusão e morte e traição e mostra filho matando mãe e irmão e as vezes até o pai, mostra acidentes e roubos e sequiestros e assaltos, e por mim não deveria passar esses programas na TV é muito ruim para o futuro de uma pessoa. (Maxwell, idade não indicada)

As novelas do 4:

Senhora do Destino dá mal exemplo de rolbar [roubar] os filhos de outra pessoa: [.]

Cabocla dá mal exemplo de matar as pessoas.

As novelas do 11:

Seus olhos: da [dá] mal [mau] exemplo de fumar maconha e matar.

Jornal dá mal [mau] exemplo porque aparece muita querra [guerra] e morte, assalto, rroubo [roubo] etc.

Eu acho que a Rede Globo tem que sabe [saber] que um programa desse não é bom colocar na tv porque tem muita violência e [é] um programa que não tem futuro na tv.

Vamos saber o que e [é] bom pra gente ver na tv. (Andrezza, idade não indicada)

Elas temem que esses maus exemplos possam vir a ser seguidos (ou imitados) pelos espectadores que consideram mais vulneráveis à influência dessa mídia, mas consideram-se pessoalmente imunes a eles, já que sabem distinguir o certo do errado e sabem escolher o que podem e o que não podem aprender com a televisão.

As crianças acreditam que a televisão tem um papel social a desempenhar na educação das pessoas, e têm propostas de como ela deve cumpri-lo; apresentam reflexões sofisticadas a respeito do conteúdo do que é exibido e se mostram capazes de estabelecer diálogos criativos com a programação, apesar dos constrangimentos impostos a sua criatividade e reflexão pelo sistema padronizado (muitas vezes, pasteurizado) de produção televisiva.

Elas adoram ver televisão e não se importam com o que os adultos dizem a esse respeito:

A tevê é muito boa, eu adoro a televisão, principalmente, os programas que ela passa para mim. Para os adultos, a televisão é ruim, porque eles acham que se as crianças ficarem assistindo televisão as crianças não aprendem coisas boas e nada da escola. Hoje vou chegar em casa, vou ligar minha televisão e vou assistir. Acabou a minha história. (Camila, 12 anos, estudante de uma escola particular do Rio de Janeiro)

Elas gostam de quase todos os gêneros de programas veiculados pela televisão, mas isso não faz delas espectadores idiotizados, pois fazem críticas interessantes, pertinentes e bem elaboradas ao que consideram ruim, pernicioso ou inadequado.

As crianças analisam a televisão com muita competência, quase como especialistas; demonstram conhecê-la também pelo lado de dentro, conhecem as linguagens de que ela se utiliza, sua estrutura de produção, sua lógica interna e modos de intervenção. Fazem comparações entre os diversos canais e programas, tecem considerações pertinentes sobre eles, comparam grades de programação segundo a qualidade dos produtos, não necessariamente os que são endereçados a elas, tecem críticas mais ou menos elaboradas a esse ou àquele produto em especial, e identificam com relativa facilidade o endereçamento dos produtos veiculados. Percebem a diferença entre novelas e seriados e entre seriados brasileiros e norteamericanos (tais como OC, Friends, Kenan e Kell); sabem a diferença entre um produto "engraçado" e programas "humorísticos", e mencionam ainda a nacionalidade de seus desenhos prediletos (se é japo- 
nês, norte-americano ou brasileiro), avaliando a qualidade de cada um deles.

Essa expertise parece ter sido conquistada, mais do que adquirida em razão da participação em atividades educativas realizadas com esse objetivo, pois são poucas e pontuais as ações institucionais destinadas ao que se convencionou chamar de educação para os meios. Em conformidade com estudos recentes realizados no Brasil (Pereira, 2003; Fernandes, 2003; Salgado, 2005), os textos que recebemos sugerem que os conhecimentos de que as crianças lançam mão para dialogar com a televisão advêm, principalmente: a) do convívio diário, prolongado e precoce com a televisão, que, articulado a muitas conversas sobre o tema com os pares e com os adultos, lhes concede um domínio das linguagens e formatos televisivos; b) do que lêem e ouvem a respeito da televisão; c) do uso recorrente e paciente do controle remoto, não apenas para "zapear", 12 como fazem adolescentes e adultos, mas para escolher o que desejam ver (os textos que recebemos nos informam que elas vêem diferentes canais ao longo do dia, e que sabem, exatamente, o horário e o canal em que são exibidos seus programas favoritos).

Comentando pesquisas sobre audiência infantil realizadas na Europa, Bailén (2002, p. 179-180) menciona resultados que confirmam essa expertise entre os telespectadores mais assíduos e apaixonados pela televisão, que, segundo ela, compõem hoje a geração dos "hijos de la televisión":

Estos disponen de una competencia de lectura tipicamente televisiva, "tributarias del medio y no derivadas de la transferencia a la televisión de competencias adquiridas en otro lugar: en el cine o en la lectura (Bechelloni, 1990:57). Son personas que han nascido con la televisión y se relacionan con ella de modo natural. Aunque pudieron tener

${ }^{12}$ Conceito amplamente utilizado nos estudos de recepção televisiva para descrever certa forma de ver que implica trocar freqüentemente de canal utilizando o controle remoto, sem assistir a nenhum programa integralmente (Sarlo, 1997). vetado el consumo de televisión durante su infancia, esto no les impidió entender desde muy pequeños el manejo de los paparatos. (Garcia, 1996)

Cabe, portanto, abandonarmos nossos preconceitos e estarmos mais atentos ao que esses experts em televisão têm a nos dizer sobre o assunto.

\section{Referências bibliográficas}

ADORNO, Theodor; HORKHEIMER, Max. Dialética do esclarecimento. Fragmentos filosóficos. Trad. Guido de Almeida. Rio de Janeiro: Jorge Zahar, 1985.

ALEGRIA, João; DUARTE, Rosália. Um sonho, um belo sonho: considerações sobre a gênese das relações entre educação e cinema no Brasil. Rio de Janeiro, 2005. Mimeografado.

BAILÉN, Amparo Huertas. La audiencia investigada. Barcelona: Gedisa, 2002.

FERNANDES, Adriana H. As mediações na produção de sentidos das crianças sobre os desenhos animados. 2003. Dissertação (Mestrado em Educação) - Departamento de Educação, Pontifícia Universidade Católica do Rio de Janeiro, Rio de Janeiro, 2003. Disponível em: <www.dbd.puc-rio.br>.

FUENZALIDA, Valerio. Televisión abierta y audiencia en América Latina. Buenos Aires: Grupo Editorial Norma, 2002.

GALERA, Carmen García. Televisión, violencia e infancia: el impacto de los medios. Barcelona: Gedisa, 2000.

LEFEBVRE, Martin. Psycho: de la figure au musée imaginaire théorie e pratique de l'acte de spectature. Paris: L'Harmattan; Canada: Harmattan, 1997.

LIVINGSTONE, Sonia. Review of television, childhood and the home: a history of the making of the child television audience in Britain. Sociology, v. 54, n. 2, p. 25-45, 2003.

MARTIN-BARBERO, J. La educación desde la comunicación. Buenos Aires: Grupo Editorial Norma, 2002.

Os exercícios do ver. São Paulo: Editora Senac, 2001. Dos meios às mediações. Comunicação, cultura $\mathrm{e}$ hegemonia. Rio de Janeiro: Editora UFRJ, 2003.

Ofício de cartógrafo. Travessias latino-americanas de comunicação na cultura. São Paulo: Loyola, 2004.

OROZCO GÓMEZ, Guillermo. La audiencia frente a la pantalla. Una exploración del proceso de recepción televisiva. Diálogos de la Comunicación, n. 30, p. 55-63, jun. 1991. 
. Televisión, audiencias y educación. Buenos Aires: Grupo Editorial Norma, 2001.

PEREIRA, Rita M. Ribes. Nossos comerciais, por favor! Infância, televisão e publicidade. 2003. Tese (Doutorado em Educação) - Departamento de Educação, Pontifícia Universidade Católica do Rio de Janeiro, Rio de Janeiro, 2003. Disponível em: <www.dbd.puc-rio.br>.

PORTO, Tânia (Org.). Redes em construção: meios de comunicação e práticas educativas. Araraquara: JM Editora, 2003.

PUIG, Josep Maria. A construção da personalidade moral. São Paulo: Ática, 1998.

SALGADO, Raquel G. Ser criança e herói no jogo e na vida: a infância contemporânea entre o brincar e os desenhos animados. 2005. Tese (Doutorado em Psicologia) - Departamento de Psicologia, Pontifícia Universidade Católica do Rio de Janeiro, Rio de Janeiro, 2005. Disponível em: 〈www.dbd.puc-rio.br〉.

SARLO, Beatriz. Cenas da vida pós-moderna. Rio de Janeiro: Editora UFRJ, 1997.

SILVERSTONE, Roger. Por que estudar a mídia? São Paulo: Loyola, 2002.

Televisión y vida cotidiana. Buenos Aires: Amorrortu, 1994.

ROSÁLIA DUARTE, doutora em educação pela Pontíficia Universidade Católica do Rio de Janeiro (PUC-Rio), é professora da mesma instituição, na qual coordena o Grupo de Pesquisa Educação e Mídia (GRUPEM). Publicações recentes: Cinema \& educação (Belo Horizonte: Editora Autêntica, 2002); em co-autoria com LEITE, Camila e MIGLIORA, Rita. Produção de sentido e construção de valores na experiência com o cinema (In: SETTON, Maria da Graça Jacinto (Org.). A cultura da mídia na escola: ensaios sobre cinema e educação. São Paulo: EDUSP; Annablume, 2004, p. 37-52); Do ato de espectatura ao museu de imagens: produção de sentido na experiência com o cinema (Educação \& Realidade, v. 30, n. 1, p. 25-43, jan./jun. 2005). Pesquisa em andamento, com financiamento do CNPq: "Significados e valores na relação das crianças com produtos audiovisuais". E-mail: rosalia@edu.puc-rio.br
CAMILA LEITE, mestre em educação pela Pontifícia Universidade Católica do Rio de Janeiro (PUC-Rio), é coordenadora do Instituto de Artes Tear (Ponto de Cultura vinculado ao Ministério da Educação) e membro do Grupo de Pesquisa Educação e Mídia (GRUPEM). Publicações recentes: em co-autoria com MIGLIORA, Rita: A troca sincrônica de mensagens (MSN) na socialização de crianças e adolescentes (In: Seminário Brasileiro de Estudos Culturais e Educação, 2. Anais... 1 CD-ROM. Canoas: Editora da ULBRA, 2006, 23 p.); em co-autoria com DUARTE, Rosália e MIGLIORA, Rita. Produção de sentido e construção de valores na experiência com o cinema (In: SETTON, Maria da Graça Jacinto (org.). A cultura da mídia na escola: ensaios sobre cinema e educação. São Paulo: EDUSP; Annablume, 2004, p. 37-52). Email: cmila@ogamita.com.br

RITA MIGLIORA, mestranda em educação pela Pontifícia Universidade Católica do Rio de Janeiro (PUC-Rio) é membro do Grupo de Pesquisa de Educação e Mídia (GRUPEM). Publicações recentes: em co-autoria com DUARTE, Rosália e LEITE, Camila. Produção de sentido e construção de valores na experiência com o cinema (In: SETTON, Maria da Graça Jacinto (org.). A cultura da mídia na escola: ensaios sobre cinema e educação. São Paulo: EDUSP; Annablume, 2004, p. 37-52); em co-autoria com DUARTE, Rosália. O que pensam as crianças brasileiras sobre o que aprendem com a tevê (In: Congresso Hispanoluso de Comunicación e Educación "La televisión que queremos. Hacia una TV de calidad", Anais... 1 CD-ROM. Huelva: Editora da Universidade de Huelva, novembro de 2005, 12p.); em co-autoria com LEITE, Camila. A troca sincrônica de mensagens (MSN) na socialização de crianças e adolescentes. (In: Seminário Brasileiro de Estudos Culturais e Educação, 2. Anais... 1 CD-ROM. Canoas: Editora da ULBRA, 2006, 23 p.). E-mail: ritapeixotom@yahoo.com.br

Recebido em março de 2006 Aprovado em julho de 2006 
Rosália Duarte, Camila Leite e Rita Migliora

Crianças e televisão: o que elas pensam sobre o que aprendem com a tevê

Este artigo apresenta os resultados de uma pesquisa realizada pelo Grupo de Pesquisa em Educação e Mídia, da Pontifícia Universidade Católica do Rio de Janeiro (PUC-RJ), em 2004, que teve como objetivo descrever e compreender as relações que as crianças estabelecem com a televisão, pelo ponto de vista delas. O estudo teve como suporte empírico textos escritos por mais de quatrocentas crianças da Região Sudeste, com idades entre 8 e 12 anos, nos quais elas expressam o que pensam sobre o que vêem na tevê. Os procedimentos analíticos dos textos das crianças foram estruturados a partir de eixos temáticos extraídos deles. Este artigo privilegia o tema "o que as crianças pensam sobre o que aprendem com a tevê".

Palavras-chave: crianças; televisão; significação; valores

Children and television: what they think about what they learn from televison

This article presents the results of a research carried out in 2004 by the Research Group in Education and Media, from the Pontificate Catholic University of Rio de Janeiro (PUCRio), which set out to describe and understand the relationship between children and television, from the children's point of view. The empirical support for this study were texts written by more than four hundred children from the Southeast Region, in the 8 to 12 year age range, in which they express what they think about what they see on television. The analytical procedures were structured on themes taken from the children's texts. This article focuses on the theme "what children think about what they learn from $T V$ ".

Key words: children; television; signification; values

Niños y televisión: lo que ellos piensan sobre lo que aprenden con la televisión

Este artículo presenta los resultados de una encuesta realizada por el Grupo de Pesquisa en Educación y Medios de Comunicación, de la Pontificia Universidad Católica de Río de Janeiro (PUC-Río), en 2004, que tuvo como objetivo describir y comprender las relaciones que los niños establecen con la televisión, desde el punto de vista de ellos. El estudio tuvo como soporte empírico textos escritos por más de cuatrocientos niños de la Región Sudeste, con edades entre 8 y 12 años, en los que ellos expresan lo que piensan sobre lo que ven en la tele. Los procedimientos analíticos de los textos de los niños fueron estructurados a partir de ejes temáticos extraídos de los mismos. Este artículo privilegia el tema "lo que los niños piensan sobre lo que aprenden con la tele".

Palabras claves: niños; televisión; significación; valores 